\title{
ESTABELECIMENTO DE CONDIÇÕES DE CULTIVO DE UMA CEPA DE Trichosporon sp ISOLADA DE MANIPUEIRA*
}

\author{
LUIZA DE MARILLAC AZEVEDO CORTÉS EFING ** \\ GILVAN WOSIACKI ***
}

\begin{abstract}
Buscou-se estabelecer as condições de cultivo de uma cepa de Trichosporon $s p$ isolada de manipueira, com vistas a obter maior quantidade de biomassa com máximo aproveitamento do amido hidrolisado do meio de cultivo. Para operacionalização dos objetivos foi utilizado um meio de composição definida, contendo $20 \mathrm{~g} / \mathrm{L}$ de amido hidrolisado e $20 \mathrm{ppm}$ de ácido cianídrico, além de $5 \mathrm{~g} / \mathrm{L}$ de extrato de levedura, 3,77 g/L de $\left(\mathrm{NH}_{4}\right)_{2} \mathrm{SO}_{4}, 0,11 \mathrm{~g} / \mathrm{L}$ de $\mathrm{KH}_{2} \mathrm{PO}_{4}$, $3,7112 \mathrm{~g} / \mathrm{L}$ de $\mathrm{MgSO}_{4} 7 \mathrm{H}_{2} \mathrm{O}, 3,1915 \mathrm{~g} / \mathrm{L}$ de $\mathrm{KCl}, 0,6223 \mathrm{~g} / \mathrm{L}$ de $\mathrm{CaCl}_{2}, \quad 0,1096 \mathrm{~g} / \mathrm{L}$ de $\mathrm{FeSO}_{4} .7 \mathrm{H}_{2} \mathrm{O}, 0,0106 \mathrm{~g} / \mathrm{L}$ de $\mathrm{ZnSO}_{4} .7 \mathrm{H}_{2} \mathrm{O}, 0,0081 \mathrm{~g} / \mathrm{L}$ de $\mathrm{CoCl}_{2} .6 \mathrm{H}_{2} \mathrm{O}, 0,0049 \mathrm{~g} / \mathrm{L}$ de $\mathrm{MnSO}_{4} \cdot \mathrm{H}_{2} \mathrm{O}$ e $0,0039 \mathrm{~g} / \mathrm{L}$ de $\mathrm{CuSO}_{4} 5 \mathrm{H}_{2} \mathrm{O}$. Os experimentos programados contemplaram como variáveis de saída a quantidade de biomassa produzida e o açúcar residual. Os resultados comprovaram que esta levedura apresenta metabolismo oxidativo, necessitando de oxigênio para o seu desenvolvimento, o qual é semelhante tanto a $20^{\circ} \mathrm{C}$, quanto a $30{ }^{\circ} \mathrm{C}$. Em presença de $\mathrm{KCN}$ seu desenvolvimento é mais lento, porém atinge os mesmos patamares alcançados na fermentação conduzida na sua ausência.
\end{abstract}

\section{INTRODUÇÃO}

O processo industrial visa a transformação de matéria-prima em produto, com o objetivo de aumentar seu valor comercial. No entanto, além do produto, que é a intenção principal da indústria, são gerados resíduos não intencionais, cuja recuperação nem sempre é de interesse para a empresa, dado o ônus econômico que representa. O resíduo industrial, uma vez gerado, não pode ser acumulado indefinidamente no local em que é produzido e, usualmente, é liberado no meio ambiente (água dos rios, ar ou solo). Para minimizar os efeitos causados pelas descargas residuárias vários processos podem ser empregados, como a recuperação de materiais, a modificação dos processos de fabricação e transporte, armazenagem em locais adequados e, inclusive, o tratamento específico do resíduo.

Parte de dissertação de mestrado em Tecnologia Química, Área de Concentração em Alimentos, Universidade Federal do Paraná.

** Professora Assistente, Departamento de Farmácia e Bioquímica, Universidade Católica do Paraná, Curitiba - PR.

*** Professor Titular, Departamento de Zootecnia e Tecnologia de Alimentos, Universidade Estadual de Ponta Grossa, PR e Pesquisador 1-B do CNPq. (e-mail: wosiacki@centerline.com.br). 
O aproveitamento industrial da mandioca para a produção de farinha, de féculas e de polvilho azedo, gera resíduos líquidos e sólidos que, se dispensados sem tratamento, apresentam forte impacto ambiental em função da grande quantidade de matéria orgânica e da toxicidade decorrente da presença de compostos cianogênicos. O efluente liberado da indústria, na forma de água de prensagem (originada durante o processo de prensagem da massa ralada) e na de água de extração (agregada no processo de separação do amido da massa ralada), se for dispensado em rios, causa aumento da demanda bioquímica de oxigênio (DBO) com conseqüente diminuição da sobrevivência de peixes e plantas (CEREDA, 1972).

A potencialidade de tratamento e utilização da água residual de fecularias é um tema já investigado há bastante tempo (CEREDA, 1972). O tratamento pode ser efetivado por métodos de lodo ativado, de digestão anaeróbia, de valos de oxidação ou de lagoas de estabilização (BRANCO \& HESS, 1975), levando-se em consideração que alguns microrganismos estão aptos a utilizar compostos orgânicos e sais minerais como nutrientes para seu crescimento. No caso da manipueira, a microflora é vasta e o crescimento microbiano é favorecido pela coexistência de componentes amilolíticos e fermentativos, produzindo biomassa pouco conhecida em termos técnicos e científicos. Para o aproveitamento dos resíduos, por outro lado, torna-se necessário averiguar as possibilidades em diferentes processos agro-industriais, tendo sua aplicação como herbicida, nematicida e inseticida sido proposta, bem como seu uso em ferti-irrigação (FIORETTO, 1984; PONTE \& FRANCO, 1989).

A manipueira, como é chamado o efluente líquido das indústrias de processamento de mandioca, pode ser considerada como meio propício para cultivo de alguns microrganismos, em especial aqueles resistentes ao cianeto (BRASIL et al., 1982; CEREDA et al., 1981), entre os quais se inclui o Trichosporon sp. Alguns parâmetros de seu crescimento já foram investigados (CEREDA et al., 1984) em condições de fermentação submersa, tanto em meio de composição definida (SICHIERI, 1986) quanto em manipueira (FIORETTO \& CEREDA, 1987). O sistema de fermentação em meio semi-sólido também foi investigado (FIORETTO et al., 1988) usando-se resíduos industriais. Já foi relatado, por outro lado, na literatura especializada, que este microrganismo apresenta o mesmo nível de produção de biomassa, quer no meio contendo glucose quer no meio contendo dextrinas (FIORETTO et al., 1985), produzindo mais óleo unicelular no último caso. Os processos de fermentação em superfície de Trichosporon $s p$, por outro lado, com as vantagens e desvantagens inerentes, ainda não foram investigados com relação ao estabelecimento de parâmetros facilmente monitoráveis no ambiente industrial. 
O presente trabalho visou a determinação da influência de variáveis de entrada, como a razão superfície/volume, a presença de cianeto de potássio e a temperatura de incubação, sobre variáveis de saída, como a produção de biomassa e a diminuição do teor de açúcar no sistema. Variáveis de saída derivadas também foram avaliadas, como a bioconversão [produção de biomassa por grama de açúcar consumido] e o indicador do processo [proposto como a produção de biomassa por açúcar residual].

Os experimentos foram planejados no sentido de obter informações sobre parâmetros tecnológicos para o aproveitamento do resíduo industrial, manipueira, como meio de cultura para produção de biomassa de uma cultura de Trichosporon $s p$ utilizando um meio de composição química definido à sua semelhança visando, desta forma, padronizar as condições de trabalho com fermentação de superfície. As metas experimentais estabelecidas foram: [1] maximizar a produção de biomassa microbiana e [2] minimizar o teor de açúcar residual no meio de cultura. A razão entre estas duas variáveis foi proposta como indicador para monitoração dos experimentos.

\section{MATERIAL E MÉTODOS}

\subsection{MATERIAL}

O material compreendeu o microrganismo e produtos químicos e biológicos. A cepa utilizada foi isolada de águas residuais de farinheira na região mandioqueira de Morretes (PR) e tipificada como Trichosporon sp. Foram usados produtos químicos de pureza pro analise e enzimas amilolíticas cedidas pela NOVO NORDISK DO BRASIL.

\subsection{MÉTODOS}

A metodologia utilizada para a realização dos experimentos envolveu a manutenção da cultura de microrganismo, o preparo das soluções para fermentação, o preparo do meio de fermentação, o preparo do inóculo, os procedimentos analíticos para análises físico-químicas e interpretação estatística, além do estabelecimento das condições de fermentação.

\subsubsection{Manutenção da cultura de microrganismo}

As cepas de Trichosporon sp cresceram em meio, inclinado, de ágarbatata-dextrose (BDA) contendo cianeto de potássio $(20 \mathrm{mg} / \mathrm{L})$, a $20^{\circ} \mathrm{C}$ durante 72 horas, e depois conservadas a temperatura de geladeira. Para 
sua utilização, as culturas do microrganismo foram deixadas a temperatura ambiente durante 3 horas, tendo sido observado o seu grau de pureza por inspeção em microscópio de luz, com e sem coloração de GRAM.

\subsubsection{Preparo das soluções para fermentação}

Foram utilizados meios de fermentação preparados a partir de soluções isoladas, denominadas de solução a) dextrinas - amido hidrolisado, b) sais e c) cianeto de potássio. O preparo da solução de amido compreendeu o uso de amilases na etapa de liquefação, conduzida em $\mathrm{pH} 5,5$, a temperatura de ebulição durante 30 minutos, e na de sacarificação, em pH 4,0 , a $50^{\circ} \mathrm{C}$ durante três horas. Após hidrólise a solução foi distribuída em frascos, esterilizada e armazenada a temperatura ambiente. A solução de sais, em concentração dupla, com pH final 5,5 continha, por litro, $10,00 \mathrm{~g}$ de extrato de levedura, 7,4224 $\mathrm{g}$ de $\mathrm{MgSO}_{4} .7 \mathrm{H} 2 \mathrm{O}, 6,3830 \mathrm{~g}$ de $\mathrm{KCl}, 1,2446$ $\mathrm{g}$ de $\mathrm{CaCl}_{2}, 0,2192 \mathrm{~g}$ de $\mathrm{FeSO}_{4} .7 \mathrm{H}_{2} \mathrm{O}, 0,0212 \mathrm{~g}$ de $\mathrm{ZnSO}_{4} \mathrm{H}_{2} \mathrm{O}, 0,0162 \mathrm{~g}$ de $\mathrm{CoCl}_{2} \cdot 6 \mathrm{H}_{2} \mathrm{O}, 0,0098 \mathrm{~g}$ de $\mathrm{MnSO}_{4} \cdot \mathrm{H}_{2} \mathrm{O}, 0,0078 \mathrm{~g}$ de $\mathrm{CuSO}_{4} \cdot 5 \mathrm{H}_{2} \mathrm{O}, 0,754 \mathrm{~g}$ de $\left(\mathrm{NH}_{4}\right)_{2} \mathrm{SO}_{4}$ e $0,022 \mathrm{~g}$ de $\mathrm{KH}_{2} \mathrm{PO}_{4}$. A solução de cianeto de potássio foi preparada por dissolução em água estéril alcalinizada, no momento do uso.

\subsubsection{Preparo do meio de fermentação}

Para elaboração do meio de fermentação foram assepticamente misturadas as soluções de amido hidrolisado ( $50 \%$ do volume final) e de sais ( $50 \%$ do volume final), tendo sido desconsiderado o erro experimental causado pela adição de $1 \mathrm{~mL}$ de solução de cianeto de potássio. $\mathrm{O}$ meio de fermentação assim constituído foi inoculado com $2 \%$ (v/v) de meio de cultura em crescimento exponencial e incubado sem agitação, mas com controle de temperatura.

\subsubsection{Preparo do inóculo}

As células do microrganismo foram adaptadas ao meio líquido por incubação, a $20{ }^{\circ} \mathrm{C}$, de meio de cultura inoculado a partir de culturas mantidas em meio agarizado, por transferência com alça de platina. Este meio de adaptação apresentou teor de KCN de 20 ppm. Após 3 dias de incubação a $20^{\circ} \mathrm{C}$, a transferência de células adaptadas para os meios de cultura experimentais foi feita com pipetas esterilizadas, a $2 \%(\mathrm{v} / \mathrm{v})$. 


\subsubsection{Procedimentos analíticos}

O meio fermentado foi filtrado e as análises compreenderam a determinação gravimétrica da biomassa produzida (após secagem a $104{ }^{\circ} \mathrm{C}$ ), as de $\mathrm{pH}$ realizadas em pHmetro digital, as de acidez por titulometria efetuadas de acordo com métodos oficiais de análise, e de açúcares pelo método do fenol sulfúrico (DUBOIS et al., 1956).

\subsubsection{Estabelecimento das condições de fermentação}

A influência da razão superfície/volume sobre o processo fermentativo foi investigada tendo sido utilizados frascos de diferentes formas e capacidades contendo diferentes volumes do meio de fermentação, conforme segue:

\begin{tabular}{lcc}
\hline Tipo de frasco (Pirex) & Capacidade (em mL) & Volume de meio (em mL) \\
\hline Copo de Becker & 1000 & 900 \\
Copo de Becker & 1000 & 750 \\
Copo de Becker & 1000 & 500 \\
Balão de fundo chato & 2000 & 480 \\
Copo de Becker & 1000 & 250 \\
Erlenmeyer & 500 & 180 \\
Garrafa & 4000 & 680 \\
Garrafa & 2000 & 440 \\
Copo de Becker & 1000 & 100 \\
\hline
\end{tabular}

A incubação ocorreu em estufa a temperatura de $20^{\circ} \mathrm{C}$ durante dez dias. A influência da temperatura foi observada a $20^{\circ} \mathrm{C}$ e a $30^{\circ} \mathrm{C}$, em copos de Becker de $1000 \mathrm{~mL}$ de capacidade, contendo $250 \mathrm{~mL}$ de meio de fermentação de composição definida, com $20 \mathrm{~g} / \mathrm{L}$ de amido hidrolisado e 20 ppm de KCN, durante dez dias, com avaliações diárias, em duplicata, do desenvolvimento do processo fermentativo. A influência do cianeto de potássio sobre o crescimento microbiano foi investigada com fermentações em copos de Becker de $1000 \mathrm{~mL}$ de capacidade, contendo $250 \mathrm{~mL}$ de meio com 187 ppm de KCN. 
A cepa de Trichosporon $s p$, isolada e purificada da manipueira, foi conservada em meio agarizado contendo $20 \mathrm{ppm}$ de cianeto de potássio, visando manter sua adaptação ao agente tóxico. Nesta condição, o crescimento do microrganismo foi comprovado pela observação de seu desenvolvimento na superfície com aspecto uniforme, de coloração creme e aspecto rugoso. Durante as primeiras 24 horas de incubação, o desenvolvimento apresentado pelo microrganismo foi observado apenas microscopicamente. Após este período foi possível observar visualmente o micélio e após 72 horas, a biomassa cobria toda a superfície do meio de cultura.

No processo de fermentação em superfície, a biomassa produzida permanece flotando e torna-se mais espessa à medida em que os teores de nutrientes diminuem. Esta massa micelial pode ser facilmente separada do meio líquido por filtração simples, em papel qualitativo. Os ensaios de crescimento desta cepa de levedura nestas condições, a $20^{\circ} \mathrm{C}$ e durante 72 horas, em superfície, foram típicos e sempre utilizados para inóculo dos experimentos. Assim pode ser comprovado que a cepa de Trichosporon $s p$, isolada da manipueira, cresce no meio de cultura quimicamente definido, mesmo contendo cianeto de potássio.

O processo fermentativo estático ou em superfície foi escolhido considerando-se a facilidade na separação da biomassa, que torna 0 processo mais econômico uma vez que a película superficial pode ser separada do líquido fermentado, havendo economia de energia equivalente à agitação e aeração, que seria consumida em processos submersos aerados. Nestas condições foram realizados estudos cinéticos, com vistas a determinar a influência da razão superfície/volume, da temperatura e da presença de cianeto no processo fermentativo, utilizando-se dextrinas amido hidrolisado como fonte de carbono, e enriquecendo-se o meio com extrato de levedura.

O experimento com razão superfície/volume definida foi realizado com o objetivo de verificar a necessidade da participação do oxigênio no processo fermentativo. Na composição deste experimento conduziu-se o processo fermentativo em situações extremas desta razão, cujos números baixos indicam que há muito nutriente e pouco oxigênio disponível, e os números altos refletem o contrário, ou seja, pouco nutriente e bastante oxigênio disponível. Esta razão variou de 0,096 a 0,860 com coeficiente de variação de Pearson de $67,00 \%$, ou seja, suficientemente ampla para detectar influências, se houver (Tabela 1). 
TABELA 1 - INFLUÊNCIA DA RAZÃO SUPERFÍCIE/VOLUME SOBRE AS VARIÁVEIS DE SAÍDA

\begin{tabular}{lccccrrrr}
\hline $\begin{array}{c}\text { Tipo de } \\
\text { frasco }\end{array}$ & $\begin{array}{c}\text { Área } \\
\mathrm{em} \mathrm{cm}^{2} \\
{[\mathrm{~A}]}\end{array}$ & $\begin{array}{c}\text { Volume } \\
\mathrm{em} \mathrm{cm}^{3} \\
{[\mathrm{~V}]}\end{array}$ & $\begin{array}{c}\text { Razão } \\
\mathrm{A} / \mathrm{V}\end{array}$ & $\begin{array}{c}\text { Biomassa } \\
\mathrm{em} \mathrm{g/L}\end{array}$ & $\begin{array}{c}\text { Aḉćar } \\
\text { residual } \mathrm{em} \\
\mathrm{g} / \mathrm{L}\end{array}$ & $\begin{array}{r}\text { Açúcar } \\
\text { consumido } \\
\mathrm{em} \mathrm{g/L}\end{array}$ & Converão & Indicador \\
\hline 1 Becker & 86 & 900 & 0,096 & 4,0 & 11,6 & 8,40 & 0,476 & 0,345 \\
2 Becker & 86 & 750 & 0,115 & 3,0 & 10,2 & 9,80 & 0,306 & 0,294 \\
3 Becker & 86 & 500 & 0,170 & 4,0 & 10,4 & 9,60 & 0,417 & 0,385 \\
4 Balão & 130 & 480 & 0,270 & 6,0 & 8,6 & 11,40 & 0,526 & 0,698 \\
5 Becker & 86 & 250 & 0,344 & 5,6 & 10,4 & 9,60 & 0,583 & 0,538 \\
6 Erlenmeyer & 73 & 180 & 0,400 & 7,5 & 7,8 & 12,20 & 0,610 & 0,962 \\
7 Garrafa 4 L & 336 & 680 & 0,494 & 7,3 & 7,8 & 12,20 & 0,598 & 0,936 \\
8 Garrafa 2 L & 256 & 440 & 0,580 & 9,1 & 7,8 & 12,20 & 0,746 & 1,167 \\
9 Becker & 86 & 100 & 0,860 & 3,3 & 6,4 & 13,60 & 0,243 & 0,515 \\
\hline Média & & & & 5,53 & 8,96 & 11,00 & 0,500 & 0,646 \\
Desvio & & & & 2,12 & 1,64 & 1,71 & 0,149 & 0,307 \\
Coeficiente de variação, \% & & 38,36 & 18,27 & 15,53 & 29,860 & 47,530 \\
\hline
\end{tabular}

A produção de biomassa foi baixa nos três primeiros ensaios e no último, demonstrando que as condições de ensaios intermediárias foram mais propícias. No primeiro grupo pode-se considerar que há nutrientes para maior produção de micélio (mais lenta pela baixa disponibilidade de oxigênio), e no sistema com mais oxigênio os microrganismos esgotam rapidamente os nutrientes. Nas fermentações conduzidas nas condições mais adequadas [ensaios de 4 a 8] é possível observar que as quantidades de biomassa produzidas encontram-se com valores mais próximos, com pequena variação (média $=7,1 \pm 1,38$ ), de 19,5\%, o mesmo ocorrendo com os teores de açúcares do meio (média $=11,87 \pm 1,32$ ), de 11\%. A diminuição dos teores de açúcar, por sua vez, demonstra que foram consumidos preferencialmente em condições mais aeróbias, tendo atingido o maior consumo no ensaio com maior razão. O teor mais baixo encontrado, de 6,4 $\mathrm{g} / \mathrm{L}$, pode representar apenas as dextrinas limites presentes no meio e não aproveitadas nesta fase de fermentação. Os valores calculados de bioconversão indicaram valor médio de $0,500 \mathrm{~g}$ de biomassa produzida por $1 \mathrm{~g}$ de amido com coeficiente de variação elevado (de 29,86\%), indicando que há diferenciação entre as médias, embora pequena. $\mathrm{O}$ indicador proposto, relacionado à quantidade de biomassa produzida e ao teor de açúcar residual, estabelece que os ensaios intermediários foram efetivamente favorecedores do processo fermentativo. Estes resultados estão apresentados também sob a forma gráfica com a finalidade de identificar melhor os ensaios e as situações nas quais o processo desenvolveu-se com mais eficiência (os valores relativos ao 
indicador foram amplificados 20 vezes para melhor ilustração). É possível observar que, as melhores condições de fermentação segundo este parâmetro ocorrem quando a razão superfície/volume encontrava-se na faixa de 0,3 a 0,7 (Figura 1).

Para escolha do frasco a ser utilizado nos ensaios e experimentos posteriores, considerou-se a facilidade no trabalho em laboratório com a utilização dos copos de Becker de $1000 \mathrm{~mL}$, com $250 \mathrm{~mL}$ de meio de cultura. Mesmo tendo-se conhecimento de que para outros frascos os resultados de biomassa e açúcar residual foram melhores, optou-se por este para possibilitar a condução dos experimentos com valor constante de superfície/volume, necessário à execução dos ensaios seguintes. $\mathrm{Na}$ Tabela 1 este resultado está evidenciado por sombreamento.

\section{FIGURA 1 - INFLUÊNCIA DA RAZÃO SUPERFÍCIE/VOLUME NAS VARIÁVEIS DE SAÍDA}

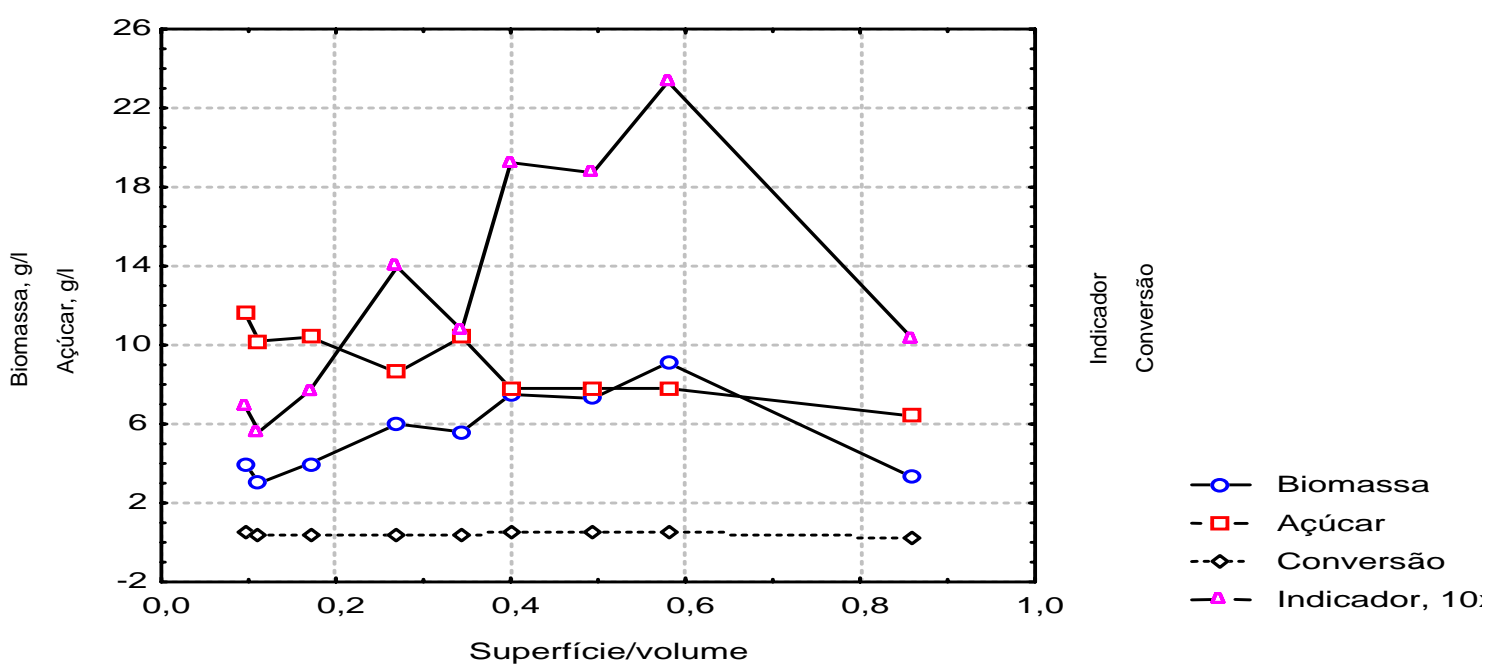

A influência da temperatura no processo fermentativo foi determinada em estudo cinético, em temperaturas de 20 e $30{ }^{\circ} \mathrm{C}$ durante 11 dias. Foi possível verificar que os valores de $\mathrm{pH}$ mostraram-se no mesmo nível de grandeza. Estes passaram do valor inicial de 4,90 (até o final mais alcalino) por decréscimo sensível durante o período, tendo sido encontrados como valores mínimos de $\mathrm{pH} 3,2$ e 3,0 a 20 e a $30^{\circ} \mathrm{C}$, respectivamente. Os valores encontrados para os ácidos totais titulados foram também semelhantes em ambos os tratamentos, oscilando entre o valor médio de 1,22 a $1,16 \mathrm{~g} / 100 \mathrm{~g}$. A produção de biomassa foi similar nos dois casos, tendo sido obtidos valores máximos de cerca de $10 \mathrm{~g} / \mathrm{L}$ no $10^{\circ}$ dia de fermentação. 
Ao final do processo, os valores de açúcares residuais foram de $3,4 \mathrm{~g} / \mathrm{L}$ e de $5,4 \mathrm{~g} / \mathrm{L}$, respectivamente, a 20 e a $30{ }^{\circ} \mathrm{C}$, o que representa diminuição de $87 \%$ e $77 \%$. Quando a fermentação é conduzida a $20^{\circ} \mathrm{C}$ esta variável torna-se favorecida se a intenção for diminuir o teor de carboidratos do meio. A conversão de carboidratos apresentou valores relativamente estáveis, com média de $0,619 \pm 0,03$ a $20{ }^{\circ} \mathrm{C}$ e de $0,682 \pm 0,03$ a $30{ }^{\circ} \mathrm{C}$. Vale dizer que há superposição destes valores e neste caso, também há certo benefício se o processo for conduzido a temperatura mais baixa, embora os resultados não difiram entre si. O indicador do processo fermentativo, por outro lado, é $75 \%$ maior quando a temperatura de incubação é de $20{ }^{\circ} \mathrm{C}$. Estes conjuntos de resultados (Tabela 2 e 3) indicam que a temperatura de fermentação em superfície interfere na avaliação do processo, o qual é beneficiado em temperatura mais baixa.

TABELA 2 - RESULTADOS DA FERMENTAÇÃO CONDUZIDA A $20^{\circ} \mathrm{C}$

\begin{tabular}{c|c|c|c|c|c|c|c}
\hline $\begin{array}{c}\text { Tempo } \\
\text { Em dias }\end{array}$ & $\mathrm{pH}$ & $\begin{array}{c}\text { Acidez em } \\
\mathrm{g} / 100 \mathrm{~mL}\end{array}$ & $\begin{array}{c}\text { Biomassa } \\
\mathrm{em} \mathrm{g} / \mathrm{L}\end{array}$ & $\begin{array}{c}\text { Açúcar } \\
\text { residual em } \\
\mathrm{g} / \mathrm{L}\end{array}$ & $\begin{array}{c}\text { Açúcar } \\
\text { consumido } \\
\text { em g/L }\end{array}$ & $\begin{array}{c}\text { Conversão } \\
\text { biomassa por } \\
\text { açúcar consumido }\end{array}$ & $\begin{array}{c}\text { Indicador } \\
\text { biomassa por } \\
\text { açúcar residual }\end{array}$ \\
\hline 0 & 4,9 & 1,19 & 0,74 & 20,00 & n.d. & n.d. & n.d. \\
1 & 4,9 & 1,19 & 0,74 & 20,00 & n.d. & n.d. & n.d. \\
2 & 3,6 & 1,18 & 5,11 & 13,80 & 6,20 & 0,824 & 0,370 \\
3 & 3,2 & 1,64 & 6,12 & 10,40 & 9,60 & 0,634 & 0,588 \\
6 & 4,1 & 1,28 & 7,45 & 8,60 & 11,40 & 0,653 & 0,866 \\
7 & 4,0 & 1,07 & 8,70 & 6,80 & 13,20 & 0,659 & 1,279 \\
10 & 5,5 & 0,49 & 9,17 & 3,60 & 16,40 & 0,559 & 2,547 \\
11 & 6,6 & 1,72 & 10,02 & 3,40 & 16,60 & 0,603 & 2,947 \\
\hline
\end{tabular}

n.d.: não determinado.

Os resultados apresentados comprovam que o microrganismo cresce tanto em temperatura de $20{ }^{\circ} \mathrm{C}$ quanto de $30{ }^{\circ} \mathrm{C}$, sendo favorecido pela temperatura mais baixa. Optou-se pela temperatura de $20^{\circ} \mathrm{C}$ para a continuidade dos estudos, já que os resultados de produção de biomassa e consumo de açúcar foram superiores aos obtidos a $30^{\circ} \mathrm{C}$. A fase estacionária, atingida aos dez dias, foi utilizada como referencial para o estabelecimento do período de fermentação. 
TABELA 3 - RESULTADOS DA FERMENTAÇÃO CONDUZIDA A $30^{\circ} \mathrm{C}$

\begin{tabular}{c|c|c|c|c|c|c|c}
\hline $\begin{array}{c}\text { Tempo em } \\
\text { dias }\end{array}$ & $\mathrm{pH}$ & $\begin{array}{c}\text { Acidez em } \\
\mathrm{g} / 100 \mathrm{~mL}\end{array}$ & $\begin{array}{c}\text { Biomassa } \\
\text { em g/L }\end{array}$ & $\begin{array}{c}\text { Açúcar } \\
\text { residual em } \\
\text { g/L }\end{array}$ & $\begin{array}{c}\text { Açúcar } \\
\text { consumido } \\
\text { em g/L }\end{array}$ & $\begin{array}{c}\text { Conversão } \\
\text { biomassa por } \\
\text { açúcar consumido }\end{array}$ & $\begin{array}{c}\text { Indicador } \\
\text { biomassa por } \\
\text { açúcar residual }\end{array}$ \\
\hline 0 & 4,9 & 1,19 & 0,74 & 20,00 & n.d. & n.d. & n.d. \\
1 & 4,9 & 1,19 & 0,74 & 20,00 & n.d. & n.d. & n.d. \\
2 & 3,7 & 1,82 & 5,86 & 13,40 & 6,60 & 0,888 & 0,437 \\
3 & 3,0 & 1,66 & 6,88 & 10,60 & 9,40 & 0,732 & 0,649 \\
4 & 3,9 & 1,31 & 7,04 & 9,60 & 10,40 & 0,677 & 0,733 \\
6 & 4,3 & 1,01 & 8,55 & 7,40 & 12,60 & 0,679 & 1,155 \\
7 & 5,6 & 0,74 & 9,96 & 5,80 & 14,20 & 0,701 & 1,717 \\
11 & 7,4 & 0,40 & 9,09 & 5,40 & 14,60 & 0,623 & 1,683 \\
\hline
\end{tabular}

n.d.: não determinado.

A Figura 2 apresenta a evolução dos valores dos quocientes biomassa/açúcar residual no experimento.

FIGURA 2 - COMPARAÇÃO DOS VALORES DO INDICADOR A 20 E A $30{ }^{\circ} \mathrm{C}$

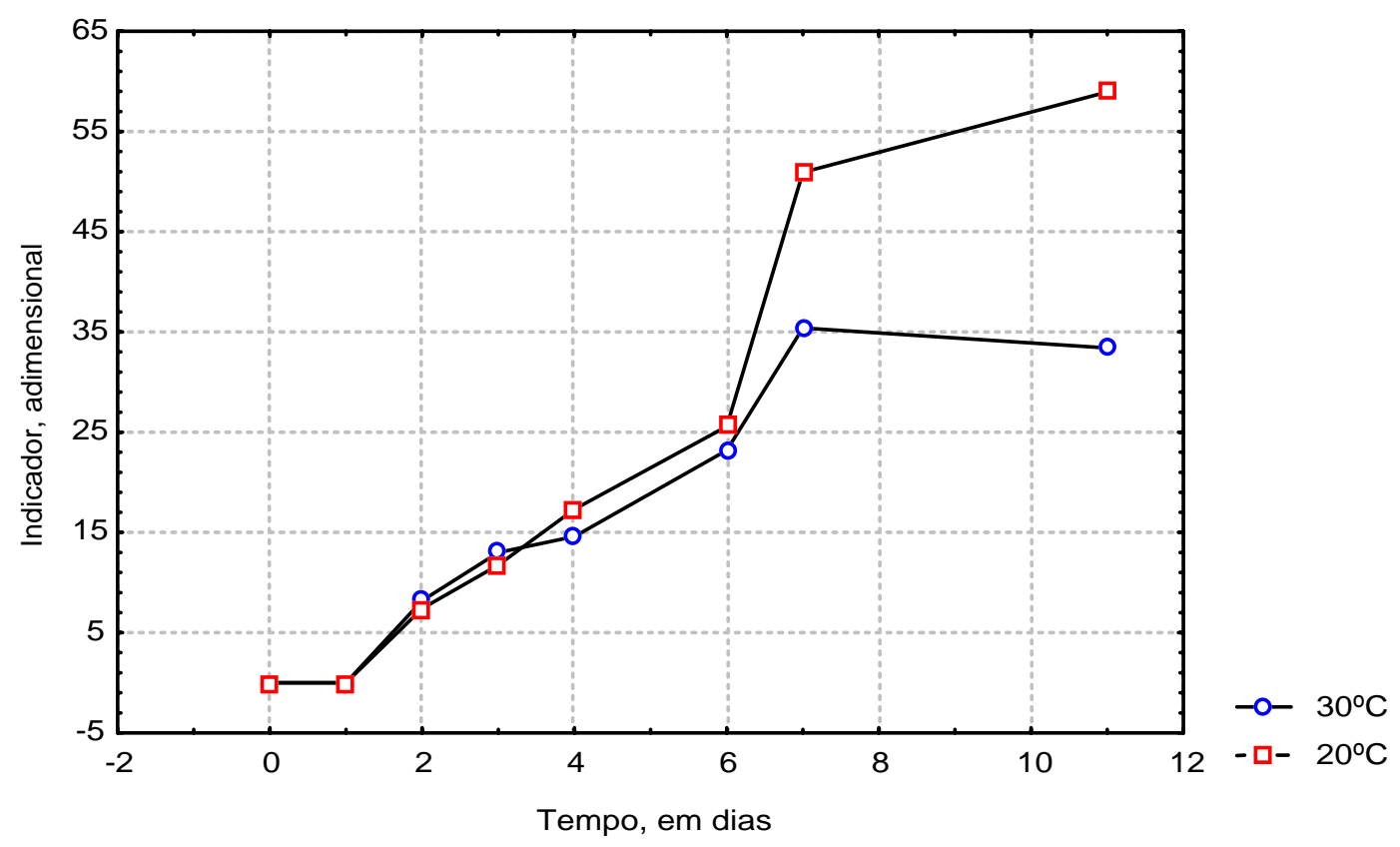


O estudo cinético, conduzido em presença e ausência de cianeto de potássio durante 11 dias, foi realizado com o objetivo de determinar diferenças entre os processos fermentativos nas duas condições, considerando-se a presença da linamarina e do ácido cianídrico em manipueira. Os valores de $\mathrm{pH}$ foram similares em ambos os processos, assim como a acidez total titulável. A produção de biomassa seguiu o mesmo padrão, com uma fase lag mais pronunciada em presença de cianeto, mas atingindo em ambos os casos os valores finais em torno de $10 \mathrm{~g} / \mathrm{L}$. Ao final do experimento os teores de açúcares residuais no meio foram semelhantes, assim como o consumo de açúcar, por conseguinte. As variáveis calculadas foram também semelhantes nos dois tratamentos.

Os resultados, expressos na Tabela 4 e 5, demonstraram que não houve diferença importante nas variáveis entre os dois tratamentos.

\section{TABELA 4 - ESTUDO CINÉTICO EM AUSÊNCIA DE CIANETO}

\begin{tabular}{c|c|c|c|c|c|c|c}
\hline $\begin{array}{c}\text { Tempo } \\
\text { em dias }\end{array}$ & $\mathrm{pH}$ & $\begin{array}{c}\text { Acidez em } \\
\mathrm{g} / 100 \mathrm{~mL}\end{array}$ & $\begin{array}{c}\text { Biomassa } \\
\text { em g/L }\end{array}$ & $\begin{array}{c}\text { Açúcar } \\
\text { residual } \\
\text { em g/L }\end{array}$ & $\begin{array}{c}\text { Açúcar } \\
\text { consumido } \\
\text { em g/L }\end{array}$ & $\begin{array}{c}\text { Conversão } \\
\text { biomassa por } \\
\text { açúcar consumido }\end{array}$ & $\begin{array}{c}\text { Indicador } \\
\text { biomassa por } \\
\text { açúcar residual }\end{array}$ \\
\hline 0 & 5,0 & 3,73 & 1,30 & 22,00 & n.d. & n.d. & n.d. \\
1 & 4,7 & 1,91 & 1,82 & 19,20 & 0,80 & 2,275 & 0,095 \\
2 & 3,7 & 2,61 & 3,88 & 18,80 & 1,20 & 3,233 & 0,206 \\
3 & 2,9 & 2,16 & 8,17 & 15,20 & 4,80 & 1,702 & 0,538 \\
5 & 2,9 & 3,01 & 8,82 & 14,60 & 5,40 & 1,633 & 0,604 \\
6 & 3,0 & 2,45 & 9,00 & 14,00 & 6,00 & 1,500 & 0,643 \\
7 & 3,1 & 2,95 & 9,88 & 13,80 & 6,20 & 1,594 & 0,716 \\
8 & 2,5 & 2,45 & 9,85 & 13,40 & 6,60 & 1,492 & 0,735 \\
9 & 2,5 & 2,32 & 10,65 & 13,00 & 7,00 & 1,521 & 0,819 \\
11 & 2,9 & 2,99 & 9,90 & 10,60 & 9,40 & 1,053 & 0,934 \\
\hline
\end{tabular}

n.d.: não determinado.

Os dados demonstram que o microrganismo é resistente ao cianeto. A adição de cianeto de potássio ao meio de cultivo nos experimentos posteriores visou manter a composição mais próxima à da manipueira, já que os resultados obtidos nos experimentos em presença e em ausência de cianeto foram semelhantes.

Os parâmetros físicos determinados como mais adequados para a realização dos experimentos foram razão superfície/volume de 0,34, temperatura de $20^{\circ} \mathrm{C}$, tempo de duração dez dias e adição de cianeto de potássio ao meio de cultura de composição química definida à semelhança da manipueira. 


\section{TABELA 5 - ESTUDO CINÉTICO EM PRESENÇA DE CIANETO}

\begin{tabular}{c|c|c|c|c|c|c|c}
\hline $\begin{array}{c}\text { Tempo } \\
\text { em dias }\end{array}$ & $\mathrm{pH}$ & $\begin{array}{c}\text { Acidez em } \\
\mathrm{g} / 100 \mathrm{~mL}\end{array}$ & $\begin{array}{c}\text { Biomassa } \\
\text { em g/L }\end{array}$ & $\begin{array}{c}\text { Açúcar } \\
\text { residual } \\
\text { em g/L }\end{array}$ & $\begin{array}{c}\text { Açúcar } \\
\text { consumido } \\
\text { em g/L }\end{array}$ & $\begin{array}{c}\text { Conversão } \\
\text { biomassa por } \\
\text { açúcar consumido }\end{array}$ & $\begin{array}{c}\text { Indicador } \\
\text { biomassa por } \\
\text { açúcar residual }\end{array}$ \\
\hline 0 & 5,0 & 3,73 & 1,30 & 20,00 & n.d. & n.d. & n.d. \\
1 & 5,4 & 1,87 & 1,30 & 19,30 & 0,70 & 1,857 & 0,067 \\
2 & 5,3 & 1,87 & 2,32 & 17,20 & 3,80 & 0,610 & 0,135 \\
4 & 3,1 & 3,01 & 7,05 & 14,20 & 5,80 & 1,216 & 0,496 \\
5 & 2,9 & 3,19 & 8,16 & 13,40 & 6,60 & 1,236 & 0,609 \\
6 & 2,9 & 2,45 & 8,68 & 12,60 & 7,40 & 1,173 & 0,689 \\
7 & 3,2 & 2,90 & 9,32 & 12,10 & 7,90 & 1,180 & 0,770 \\
8 & 2,5 & 2,67 & 9,63 & 12,10 & 7,90 & 1,219 & 0,796 \\
9 & 2,8 & 2,57 & 10,82 & 12,00 & 8,00 & 1,353 & 0,902 \\
11 & 3,2 & 3,07 & 10,41 & 11,80 & 8,20 & 1,270 & 0,882 \\
\hline
\end{tabular}

n.d.: não determinado.

\section{CONCLUSÃo}

O microrganismo Trichosporon sp, isolado da manipueira, cresce em meio de composição química definida com processo oxidativo da fonte de carbono, com melhores resultados quando a incubação do sistema é realizada a $20^{\circ} \mathrm{C}$, indistintamente na presença ou ausência de cianeto.

\section{Abstract}

The best cultivation conditions for a Trichosporon sp. strain, isolated from waste water in cassava processing was settled down in order to improve biomass production and carbohydrate consumption. The medium composition used in the surface fermentation was prepared with $20 \mathrm{~g} / \mathrm{L}$ of hydrolysed cassava starch, $20 \mathrm{ppm}$ of $\mathrm{KCN}, 5 \mathrm{~g} / \mathrm{L}$ yeast extract, $3.77 \mathrm{~g} / \mathrm{L}\left(\mathrm{NH}_{4}\right) 2 \mathrm{SO}_{4}, 0.11 \mathrm{~g} / \mathrm{L} \mathrm{KH}_{2} \mathrm{PO}_{4}, 3.7112$ $\mathrm{g} / \mathrm{L} \mathrm{MgSO}_{4} .7 \mathrm{H}_{2} \mathrm{O}, 3.1915 \mathrm{~g} / \mathrm{L} \mathrm{KCl}, 0.6223 \mathrm{~g} / \mathrm{L} \mathrm{CaCl}_{2}, 0.1096 \mathrm{~g} / \mathrm{L} \quad \mathrm{FeSO}_{4} .7 \mathrm{H}_{2} \mathrm{O}, 0.0106 \mathrm{~g} / \mathrm{L}$ $\mathrm{ZnSO}_{4} .7 \mathrm{H}_{2} \mathrm{O}, 0.0081 \mathrm{~g} / \mathrm{L} \mathrm{CoCl}_{2} \cdot 6 \mathrm{H}_{2} \mathrm{O}, 0.0049 \mathrm{~g} / \mathrm{L} \quad \mathrm{MnSO}_{4} \cdot \mathrm{H}_{2} \mathrm{O}, 0.0039 \mathrm{~g} / \mathrm{L} \mathrm{CuSO}_{4} 5 \mathrm{H}_{2} \mathrm{O}$. The experimental design comprehends, as indicator, the mycelium dry weight in $\mathrm{g} / \mathrm{L}$ and the residual sugar, also in $\mathrm{g} / \mathrm{L}$. The results showed that the strain was able to grow in both 20 and $30{ }^{\circ} \mathrm{C}$, even in the presence of cyanide, and that the oxygen is required in a supply of surface/volume ratio ranging from 0,30 to 0,60 . 


\section{REFERÊNCIAS BIBLIOGRÁFICAS}

1 BRANCO, S.M., HESS, M.L. Tratamento de resíduos. In: AQUARONE, E., BORZANI, W., LIMA, U.A. Tópicos de microbiologia industrial. São Paulo : E.Blücher, 1975. v.2, p. 4776.

2 BRASIL, O.G., CEREDA, M.P, FIORETTO, A.M.C. Indução da respiração resistente ao cianeto em microrganismos pela presença de inibidores de crescimento microbiano. Phyton, Buenos Ayres, v. 42, n. 1, p. 49-53, 1982.

3 CEREDA, M.P. Água residual das fecularias. Estado de São Paulo, Suplemento Agrícola, São Paulo, 18/06/1972.

4 CEREDA, M.P., BRASIL, O.G., FIORETTO, A.M.C.F. Microrganismos resistentes ao cianeto isolados de líquido residual de fecularias.

Phyton, Buenos Ayres, v. 41, n. 1/2, p. 197-201, 1981.

5 CEREDA, M.P., FIORETTO, A.M.C., WOSIACKI, G., SICHIERI,V.L.F.S. Parâmetros de crescimento de duas cepas de Trichosporon sp. In: SIMPÓSIO NACIONAL DE FERMENTAÇÃO, Fortaleza, 1984. Anais... Fortaleza : SBM, 1984.

6 DUBOIS, M.C. et al. Colorimetric methods for determination of sugars and related compounds. Analytical Chem., Washington, v. 28, n. 3, p. 350-56, 1956.

7 FIORETTO, R.A. Efeito da manipueira aplicada em solo cultivado com mandioca. São Paulo, 1984. Dissertação (Mestrado) Energia na Agricultura, Universidade Estadual Paulista Júlio de Mesquita Filho, Campus de Botucatu.

8 FIORETTO, A.M.C., CEREDA, M.P. Biomassa de Trichosporon. ISeleção do pH em cultivo submerso agitado. Energia na Agricultura, Botucatu, v. 2, n. 2, p. 39-43, 1987.

9 FIORETTO, A.M.C., CEREDA, M.P. Cultivo de Trichosporon em meio sólido elaborado com resíduos de indústrias de processamento de mandioca. Energia na Agricultura, Botucatu, v. 3, n. 2, p. 39-43, 1988.

10 FIORETTO, A.M.C., WOSIACKI, G., BRASIL, O.G., CEREDA, M.P. Produção de biomassa oleaginosa de Trichosporon $s p$ a partir de amido. I - Pré-tratamento enzimático. In: CONGRESSSO BRASILEIRO DE MICROBIOLOGIA, São Paulo, 1985. Anais... São Paulo : SBM, 1985. 
11 PONTE, J.J., FRANCO, O. Crise ameaça defensivo vegetal. O povo, Ceará, 19/03/1989.

12 SICHIERI, V.L.F.S. Produção e caracterização dos lipídios da biomassa de Trichosporon sp. Londrina, 1986. Dissertação (Mestrado em Ciência de Alimentos), Universidade Estadual de Londrina.

\section{Agradecimentos}

Os autores são agradecidos a Eliane D.G.Danesi e Mareci Mendes de Almeida, pela revisão do texto e a Maria Etelvina Madalozzo Ramos pela das referências bibliográficas. 